\title{
RATING METHODS FOR DYNAMIC SEATING COMFORT TO BE APPLIED WITH NUMERICAL SEAT MODELS, VIBRATION DUMMY TESTS AND PASSENGER RIDE TESTS
}

\author{
*Pankoke S, Siefert A - Woelfel Beratende Ingenieure GmbH + Co. KG, \\ Hoechberg, Germany, www.woelfel.de
}

\section{Introduction}

Seating comfort is accepted to be one of the most important properties of a passenger car in terms of customer acceptance. It can be divided into two sections: Static and dynamic seating comfort. Both static and dynamic comfort is defined by the interaction between the car seat and the occupant itself. While static comfort is mostly assessed by deriving parameters from the static pressure map between seat and occupant ${ }^{4}$, dynamic comfort evaluation is based on vibrations that act on the occupant in various ways. It is commonly accepted that vertical accelerations on top of the seat cushion, i.e. between seat and occupant, have the most influence on the occupant's comfort impressions.

However, even though these vertical accelerations can easily be determined by either using simulations with dynamic CAE models of the occupied seat or by performing ride tests with test subjects or vibration dummies, it continues to be difficult to derive objective measures from those accelerations, that relate to the occupant's comfort impression. Nevertheless, car developers need such objective scalar criteria to determine the overall comfort rating of a car or a seat. This paper presents existing and new methods of how to quantify comfort parameters of cars and seats, and shows how these methods can be used either in early phase development with CAE technologies or in hardware phases / for benchmarking with a vibration dummy.

\section{Methods for scalar / multi-scalar Comfort Rating}

\begin{tabular}{|c|c|c|c|c|c|}
\hline & Method & applied to & \multicolumn{2}{|c|}{ Definition } & Type \\
\hline 1 & ISO 2631-1 & Vehicle & \multicolumn{2}{|c|}{$r m s\left(a_{w z}\right)$} & \multirow{2}{*}{ 莺 } \\
\hline 2 & $\begin{array}{l}\text { SEAT } \\
(\text { ISO 10326-1) }\end{array}$ & Seat & \multicolumn{2}{|c|}{$S E A T=r m s\left(a_{w z}\right) / r m s\left(a_{w z, 0}\right)$} & \\
\hline 3 & $\begin{array}{l}\text { Dimensions of } \\
\text { Perception }{ }^{3} \\
\text { (see Fig. 1) }\end{array}$ & Vehicle & $\begin{array}{l}\text { Occupant-on-seat: } \\
\text { Impulse: } \\
\text { High-frequency shake } \\
\text { Body vibration: }\end{array}$ & $\begin{array}{l}\hat{A}_{1}=r m s\left(\left.a_{z}\right|_{3 \mathrm{~Hz}} ^{10 \mathrm{~Hz}}\right) \\
\hat{A}_{2}=r m q\left(\left.a_{k z}\right|_{1 \mathrm{~Hz}} ^{30 \mathrm{~Hz}}\right) \\
\hat{A}_{3}=r m s\left(\left.a_{x z, 0}\right|_{11 \mathrm{~Hz}} ^{30 \mathrm{~Hz}}\right) \\
\hat{A}_{4}=r m s\left(\left.a_{z}\right|_{1 \mathrm{~Hz}} ^{3 \mathrm{~Hz}}\right)\end{array}$ & 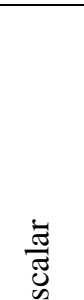 \\
\hline 4 & $\begin{array}{l}\text { STF-Parameters } \\
(\text { STF = Seat Transfer } \\
\text { Function, see Fig. 1) }\end{array}$ & Seat & $\begin{array}{l}\text { Resonance frequency: } \\
\text { Resonance magnitude } \\
\text { Isolation frequency: } \\
\text { Isolation performance }\end{array}$ & $\begin{aligned} f_{\text {res }} & =\operatorname{freq}\left(\max \left(a b s\left(\overline{H_{S}}\right)\right)\right) \\
A_{\text {res }} & =\max \left(\operatorname{abs}\left(\overline{H_{S}}\right)\right) \\
f_{\text {iso }} & =\operatorname{freq}\left(\left(a b s\left(\overline{H_{S}}\right)=1\right)\right) \\
\tilde{A}_{\text {iso }} & =\int_{f_{i s o}}^{30 H_{\tilde{s o}}}\left[a b s\left(\overline{H_{S}}\right)\right] d f\end{aligned}$ & $\stackrel{\cdot \vec{\Xi}}{\Xi}$ \\
\hline
\end{tabular}

Table 1: Overview rating methods $\left(a_{z}\right.$ : vert. acceleration on top of seat cushion; $a_{z, 0}$ : vert. acceleration at seat base; $w$ : weighted ISO 2631-1; $k$ : weighted VDI 2057-2 (1987); $\overline{H_{S}}:$ STF; $\left.a\right|_{1 H z} ^{3 H z}$ : band limits)

Methods 1 and 2 in above table are subject of standards ${ }^{1,2}$, but are not being used in automotive development processes since they are not able to differ between vibration phenomena: Only one 
scalar value is available for describing the overall comfort "properties" of a vehicle or seat. Application of the multi-scalar methods "Dimensions of Perception" as proposed in ${ }^{3}$ and "STFParameters" allows for a structured balancing of conflicting engineering targets (like resonance magnitude and isolation performance) and a summarized optimization of dynamic seating comfort with respect to differentiated occupant perceptions (like occupant-on-seat-behavior and high frequency shake).
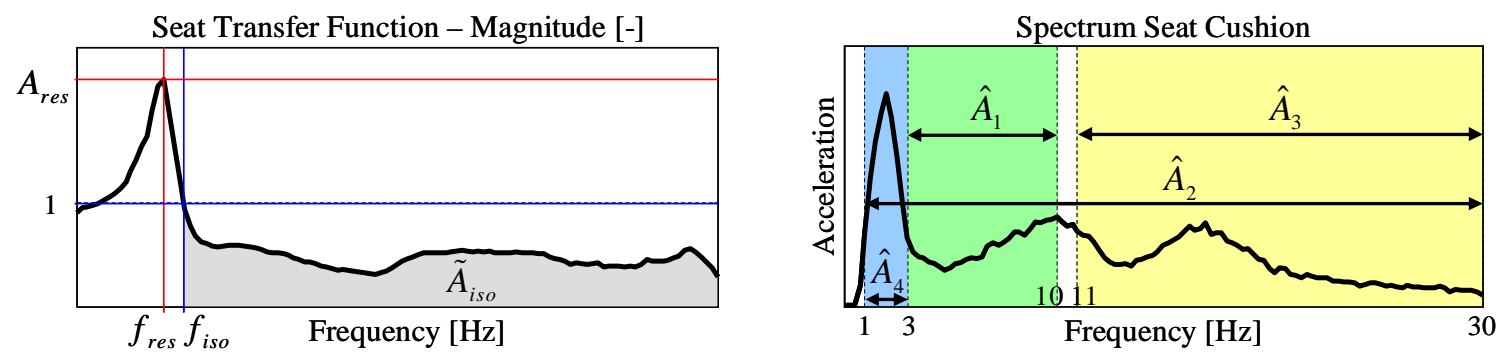

Figure 1: Left: STF-Parameters; Right: Frequency bands for perception dimensions $\hat{A}_{1}$ to $\hat{A}_{4}$

\section{Application Scenarios}

Application of any of the above mentioned rating methods requires the determination of $a_{z}$, the vertical acceleration on top of the seat cushion at the interface between occupant and seat and also the determination of $a_{z, 0}$, the vertical acceleration at the seat base. Since $a_{z}$ significantly depends on the occupant and its interaction with the seat, determination can only be done with an occupied seat. Such determination can be done in the virtual space, using CAE models of the occupied seat, e.g. with CASIMIR ${ }^{5}$, or by physical testing using vibrations dummies like MEMOSIK ${ }^{6}$ or human occupants. Thus, the rating methods are independent from where the input data (said accelerations $a_{z}$ and $a_{z, 0}$ ) result from.

\section{Discussion}

Two new methods for multi-scalar dynamic comfort rating are presented. Both methods are capable of differentiating between relevant seat and / or vehicle properties that have different effects on the occupant's comfort perception. Thus, engineering conflicts can be recognized and solved by defining OEM specific weighting (A1 to A4 in "Dimensions of perception") and targets (in "STF-Parameters"). The methods can be applied with digital and physical testing procedures for the occupied seat and are currently being integrated as post processing options into existing engineering solutions for seating comfort analysis ${ }^{6,7}$. Multi-scalarity enables the methods to be used in conjunction with established target balancing procedures like DoE.

\section{References}

1. International Organization for Standardization (1992). ISO 10326-1

2. International Organization for Standardization (1997). ISO 2631-1, $2^{\text {nd }}$ edition

3. Lennert, S. (2009). Zur Objektivierung von Schwingungskomfort in Personenkraftwagen Untersuchung der Wahrnehmungsdimensionen. Fortschritt-Berichte VDI Nr. 698 (in german)

4. Mergl, C. (2006). Entwicklung eines Verfahrens zur Optimierung des Sitzkomforts auf Automobilsitzen. PhD-Thesis, University of Munich (in german)

5. Siefert, A., Pankoke, S., Woelfel, H.-P. (2008). Virtual optimisation of car passenger seats: Simulation of static and dynamic effects on drivers' seating comfort. Int. J. Ind. Ergon. 38 (2008) 410-424

6. Woelfel Beratende Ingenieure (2010). MEMOSIK ${ }^{\circledR}$, physical vibration dummy

7. Woelfel Beratende Ingenieure (2010). CASIMIR/Automotive, seating comfort analysis software 